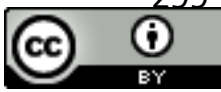

\title{
ASPECTOS METODOLÓGICOS E ÉTICOS DE UMA PESQUISA SOBRE MUDANÇA DE ATITUDES SOCIAIS DE PROFESSORES E ESTUDANTES EM RELAÇÃO À INCLUSÃO
}

\author{
Camila Mugnai Vieira ${ }^{1}$
}

Sadao Omote ${ }^{2}$ iD

\begin{abstract}
Resumo
Este artigo discute aspectos metodológicos e éticos de uma pesquisa que analisou os efeitos de uma capacitação de professores para administrar um programa informativo a seus alunos sobre as atitudes sociais de ambas as partes em relação à inclusão. São discutidas questões relacionadas a tipo de delineamento adotado e suas vantagens, momentos de mensuração utilizados (pré-teste, pós-teste e follow up), replicação intra-delineamento e série histórica desenvolvida para fortalecer a confiabilidade do estudo, os professores participantes como colaboradores na pesquisa com os alunos e a alternativa para atender a demanda ética. Concluiu-se que é possível, na concepção de uma pesquisa, levar rigorosamente em conta um delineamento cuidadoso que permita uma maior confiabilidade dos resultados e, ao mesmo tempo, criar estratégias para atender a demandas éticas, minimizando ou eliminando a possibilidade de situações excludentes durante o estudo.
\end{abstract}

Palavras-chave: Metodologia de pesquisa; Ética em pesquisa; Delineamento quaseexperimental; Pesquisas com crianças; Mudança de atitudes sociais

\section{METHODOLOGICAL AND ETHICAL ASPECTS OF A RESEARCH ON CHANGING SOCIAL ATTITUDES OF TEACHERS AND STUDENTS TOWARD INCLUSION}

\footnotetext{
${ }^{1}$ Docente e Chefe da Disciplina de Psicologia da Famema; Doutora em Educação pela UNESP/MARÍLIA. Email: camilamugnai@hotmail.com

${ }^{2}$ Livre-docente e Professor Titular em Educação Especial pela Faculdade de Filosofia e Ciências, Universidade Estadual Paulista "Júlio de Mesquita Filho" - UNESP - Campus de Marília. Professor Orientador do Programa de Pós-Graduação em Educação da Faculdade de Filosofia e Ciências, UNESP - Campus de Marília. E-mail: somote@uol.com.br
} 


\begin{abstract}
The article discusses methodological and ethical aspects of a research performed to analyze the effects of a teachers training to administer an informative program to their students on the social attitudes of both parts in relation to inclusion. They are discussed subjects referring to the type of experimental design used and its advantages, moments of attitudes measurements (pretest, post-test and follow up), intra-design replication and historical series developed to strengthen the reliability of the study, teachers as collaborators in the research with students, and the alternative to consider the ethical demands. It follows that it is possible, in the conceiving of a research, to take strictly in account a careful design that allows a better reliability of the results and, at the same time, to create strategies to consider ethical demands, minimizing or eliminating the possibility of some students exclusion during the study.
\end{abstract}

Key words: Research methodology; Research ethics; Quasi-experimental design; Surveys with children; Changing social attitudes

\title{
ASPECTOS METODOLÓGICOS Y ÉTICOS DE UNA INVESTIGACIÓN REFERENTE AL CAMBIO DE ACTITUD SOCIAL DE PROFESORES Y ESTUDIANTES CON RELACIÓN A LA INCLUSIÓN
}

\section{Resumen}

Este artículo discute aspectos metodológicos y éticos de una investigación que analizó los efectos de una capacitación de profesores para administrar un programa informativo a sus alumnos sobre las actitudes sociales de ambas partes con relación a la inclusión. Discutió cuestiones relativas al diseño adoptado, sus ventajas y coyuntura mensurable utilizada (pretest, pos-test y follow up), reiteración intraexperimento y serie histórica desarrollada para fortalecer la fiabilidad del estudio, los profesores participantes como colaboradores en la investigación con los alumnos y el dilema para atender la demanda ética. Concluyó que es posible en la concepción de una investigación, llevar en cuenta rigurosamente un delineamiento cuidadoso que permita una mayor fiabilidad de resultados y al mismo tiempo crear estrategias para atender las demandas éticas, minimizando o eliminando la posibilidad de situaciones excluyentes durante el estudio. 
Palabras clave: Metodología de investigación; Ética en investigación; Delineamiento casi experimental; Investigación con niños; Cambio de actitud social

\section{INTRODUÇÃO}

A maioria dos estudos sobre concepções e atitudes sociais indica que os professores sentem que lhes falta o preparo adequado para atuar no ensino inclusivo e apontam a necessidade de investimento na sua formação inicial, assim como em capacitações em serviço (OLIVEIRA, 2006). De acordo com Omote et al. (2005), a capacitação dos professores, além da compreensão das características e necessidades do aluno com deficiência e da utilização dos recursos para atendê-las, deve incluir também uma nova visão de ensino e de aprendizagem, fundada em atitudes favoráveis à inclusão.

Estudos devem ser ampliados no sentido de transporem simples levantamentos de dados sobre as atitudes sociais para investigações de possíveis intervenções que visem mudança das atitudes sociais em relação à inclusão. Salienta-se a fragilidade metodológica das investigações, quando não são utilizados instrumentos confiáveis ou realizados delineamentos metodológicos adequados, o que pode levar a conclusões superficiais e vagas, pautadas em meras inferências dos pesquisadores baseadas em relatos orais (OMOTE, 2003).

Gatti (2003) realizou uma análise de teses e dissertações sobre a formação de professores produzidas em dez instituições brasileiras de 1961 a 2002. Os resultados indicaram que nas décadas de 1960 e 1970 os estudos eram mais de cunho quantitativo, porém vários utilizavam instrumentos sem se preocuparem com sua fidedignidade e validade e apresentavam erros importantes em análises estatísticas. Na década de 1980 foram frequentes pesquisas qualitativas, estudos de caso, de campo e etnográficos, nos quais foram identificados muitos problemas metodológicos, como a ausência ou insuficiência da descrição da própria metodologia empregada e incoerência entre o que foi declarado e o que foi adotado de fato. A década de 1990 foi marcada pela defesa de ideias que os pesquisadores pareciam querer difundir, porém com pouca sustentação nos dados obtidos nas pesquisas. A autora apontou também que foram encontrados em todos os períodos alguns trabalhos consistentes, mas as inadequações metodológicas destacaram-se na maioria dos estudos. A partir de 1999, a autora observou um lento processo de tentativas de superar estas fragilidades.

A pesquisadora discutiu que a investigação sobre formação de professores costuma seguir certos "modismos" e apresentar pouca densidade teórica própria, teceu críticas sobre o 
imediatismo com o qual os problemas de pesquisa são elaborados, preocupados com um pragmatismo que parece justificar-se pela necessidade da resolução de problemas da realidade, porém são superficiais sob o ponto de vista de fundamentação teórica e contextualização sócio-histórica. Apontou a necessidade de investimento em perguntas de pesquisa mais densas e formulação de hipóteses mais consistentes. Fez ainda críticas tanto a pesquisas quantitativas, nas quais ocorreram apropriação acrítica de modelos de mensuração sem domínio e aprofundamento dos pressupostos e técnicas nas quais as análises baseavamse, quanto a pesquisas qualitativas que não apresentaram rigor metodológico. A forma de compreender e abordar os fenômenos é diferente a depender do tipo de pesquisa, mas há que se contar com uma consistência explicativa em toda investigação (GATTI, 2003).

García, Díaz e Rodríguez (2009) analisaram programas para mudanças de atitudes sociais em relação a pessoas com deficiências e as técnicas utilizadas em sua implementação em resumos publicados entre 1972 e 2009 em bases de dados específicas. Os autores destacaram fragilidades metodológicas em muitos trabalhos, tais como: desenhos experimentais inadequados (sem avaliação prévia à intervenção, como pré-testes ou medidas de linha de base; ausência de grupos controle; estudos apenas descritivos e sem variedade de técnicas); uso de técnicas e instrumentos de medida sem estudos prévios ou construídos para os propósitos de pesquisas específicas sem nenhuma garantia de sua confiabilidade, publicações que não descreviam os instrumentos utilizados e falta de continuidade das pesquisas, restritas a um período de tempo muito curto (apenas doze de sessenta e três programas apresentaram algum tipo de avaliação da eficácia dos procedimentos após um determinado tempo, como um follow up).

Especificamente quanto à duração das pesquisas, Santos (2006) teceu críticas ao avaliar os efeitos de muitos dos programas de intervenção, pois a maioria ocorreu em períodos de tempo curto, raramente ultrapassando, em média, quatro semanas, em encontros de uma ou duas vezes por semana. Esse quadro sugere a necessidade de se realizarem estudos longitudinais ou os que ao menos contemplem algum acompanhamento posterior ao período das intervenções.

Dentre outros problemas metodológicos que precisam ser evitados, estão: falta de garantia ou teste da equivalência entre grupos experimentais e controle, o que inviabiliza a comparação de seus resultados, e utilização de delineamentos correlacionais para sugerir relação de causalidade (DUTRA; REIS, 2016).

A revisão da literatura publicada em inglês de 1990 até a metade de 2011 sobre as crenças e atitudes da população em geral em relação à deficiência intelectual, elaborada por 
Scior (2011), apontou 75 pesquisas, sendo que somente 12 destas tratavam de intervenções para modificação de atitudes ou diminuição de estigmas. $\mathrm{O}$ autor teceu críticas a respeito do delineamento da maioria dos estudos, que se mostrou frágil, especialmente em função de alguns aspectos, como: muitas pesquisas de levantamento, sendo defendida pelo autor a necessidade de mais estudos com intervenções; amostras limitadas, sendo necessários estudos mais representativos da população; e procedimentos enviesados, o que levou o autor a defender a necessidade de maior rigor científico.

Percebe-se que todos os tipos de pesquisas requerem cuidados metodológicos. A intencionalidade do presente texto não é defender um tipo padrão de delineamento, que seja superior aos demais, e sim discutir o quanto é necessário considerar a natureza do fenômeno em estudo, as variáveis que se pretende investigar, o contexto da pesquisa e, a partir dos objetivos traçados, buscar instrumentos e adotar procedimentos o mais confiáveis possível, validados em estudos anteriores ou elaborados e testados de diferentes formas de modo a ampliar sua confiabilidade.

Além dos elementos metodológicos, aspectos éticos das pesquisas têm sido discutidos no meio acadêmico. É a Resolução 196/96 do Conselho Nacional de Saúde que rege os aspectos éticos das pesquisas envolvendo seres humanos, incluindo aqueles sujeitos que não têm condições para decidir sobre sua participação neste tipo de atividade, como as crianças. De acordo com Gaiva (2009), a resolução apresenta preocupações com a dignidade da pessoa, baseadas nos princípios fundamentais da autonomia, beneficência, não maleficência, justiça e equidade.

A gestão da conduta ética em pesquisa é gerida em três níveis: o nível regulatório, que se refere aos códigos, leis e regimentos; o nível institucional, relacionado aos órgãos que se responsabilizam pela avaliação e fiscalização da implementação dessas normas, representados especialmente pelos Comitês de Ética em Pesquisa (CEP) com seres Humanos das Universidades e demais órgãos relacionados à pesquisa no Brasil; e o nível pessoal, que se refere às condutas do próprio pesquisador, desde a elaboração do projeto, passando pela seleção dos participantes, realização de coleta e análise de dados à divulgação dos resultados (FERNANDES, 2016).

Os códigos éticos são importantes, mas não são suficientes para englobar a complexidade da prática em pesquisa (FERNANDES, 2016). Os pesquisadores deparam-se com dilemas que não são claramente previstos em normativas, que demandam reflexões e decisões cotidianas para que se garantam os princípios éticos previstos, sendo necessária a articulação entre estes níveis. 
A literatura tem indicado vários desafios relacionados à pesquisa com crianças. Há consenso de que as pesquisas devem transcorrer de modo a fortalecer os direitos das crianças, garantir seu bem-estar e cumprir os deveres dos pesquisadores (FRANCISCHINI; FERNANDES, 2016). Há dilemas, porém, que precisam ser mais amplamente discutidos. Um deles refere-se ao consentimento para pesquisa, um dos aspectos éticos da pesquisa com crianças mais discutidos. Com relação à assinatura do Termo de Consentimento Livre e Esclarecido (TCLE), é definido que, para menores de idade, ele seja assinado pelos responsáveis legais, comumente os pais das crianças. Essa imposição atende à dimensão legal e burocrática, porém há que se considerar outras dimensões, como a autoria da criança no processo, bem como as relações de poder estabelecidas entre adultos e crianças (FRANCISCHINI; FERNANDES, 2016).

O consentimento dos responsáveis é chamado de consentimento por procuração, pois reflete suas convicções, seus valores e seus desejos e não os do participante, no caso, a criança. A concepção da criança como sujeito de direitos deve abarcar o respeito às suas decisões conscientes quanto a participar ou não dos procedimentos propostos. Para tanto, há que se utilizar de linguagem e estratégias que permitam aos sujeitos de diferentes faixas etárias, em diversos estágios do desenvolvimento e condições sociais, culturais ou emocionais, compreenderem realmente o que se passa e poderem também opinar acerca de seu envolvimento na pesquisa (SIGAUD et al., 2009).

Ao se falar em consentimento, há que se considerar a complexidade das escolhas, possíveis situações de constrangimento e expectativas mútuas (FERNANDES, 2016). As relações de poder entre crianças e adultos e especificamente entre pesquisador e pesquisado precisam ser consideradas para que não haja coerção e se respeite primariamente o bem estar e a integridade da criança (FRANCISCHINI; FERNANDES, 2016). Para a obtenção do consentimento, o processo precisa ser permeado de confiança, respeito, diálogo e paciência na relação pesquisador-participante (GAIVA, 2009).

Outro desafio que se coloca na pesquisa com crianças diz respeito à seleção dos participantes. O investigador precisa cuidar dos critérios de inclusão e exclusão de determinadas crianças de modo que as justificativas sejam muito plausíveis e não haja exposição de algumas crianças frente às demais nem privação de benefícios possivelmente obtidos (FERNANDES, 2016).

Considerando ainda a proteção das crianças contra qualquer dano, a ética tradicional tem enfocado a importância de não causar dano deliberado, porém pouco se discute sobre os riscos que o impedimento imposto por adultos para participação em determinadas pesquisas 
pode causar (FERNANDES, 2016). Certa superproteção de crianças pode excluí-las de pesquisas importantes, que poderiam trazer benefícios diretos a elas como participantes e também teriam o potencial de avançar na produção de conhecimento sobre este grupo social. Deixar as crianças apenas à mercê do que está institucionalizado pode levá-las ao que Fernandes (2016) denominou de "invisibilidade epistemológica".

Percebe-se, portanto, que, para o pesquisador promover uma investigação ética, deve equilibrar os interesses dele, das crianças, dos responsáveis e da sociedade em geral, considerando a complexidade das relações sociais que influenciam esse processo (FRANCISCHINI; FERNANDES, 2016).

O presente trabalho discute os aspectos metodológicos e éticos de uma pesquisa que teve como objetivo analisar os efeitos de uma capacitação de professores para administrar um programa informativo a seus alunos sobre as atitudes sociais de ambas as partes em relação à inclusão (VIEIRA, 2014). Os resultados da pesquisa, no que se refere às mudanças de atitudes sociais dos professores e alunos neste processo de formação, podem ser consultados em Vieira (2017). O objetivo do presente artigo é o de discutir como o delineamento empregado buscou a superação de algumas limitações comuns em pesquisas semelhantes, além de atender de modo diferenciado às demandas éticas pouco discutidas na literatura.

\section{MÉTODO}

Participaram deste estudo 52 professores do ciclo I de duas escolas municipais de Ensino Fundamental de uma cidade do interior paulista, sendo 30 de uma escola (E1) e 22 de outra (E2); e 516 alunos destas escolas, sendo 317 da E1 e 199 da E2. Os estudantes cursavam do primeiro ao quinto ano. Os professores e alunos da E1 formaram o grupo experimental (GE) e os membros da E2, o grupo controle (GC).

Utilizou-se a Escala Likert de Atitudes Sociais em Relação à Inclusão (ELASI) para a coleta de dados com os professores em todas as etapas. Trata-se de um instrumento elaborado pelo grupo de pesquisa Diferença, Desvio e Estigma, da Unesp, Campus de Marília, que tem o objetivo de mensurar as atitudes sociais frente ao processo de inclusão e atende os requisitos necessários da padronização e validade (OMOTE, 2005). É constituído por duas formas equivalentes (Forma A e Forma B). Cada forma é composta por 35 itens, sendo 30 para a mensuração de atitudes sociais frente à inclusão e outros cinco itens que compõem a escala de mentira. Cada item é constituído por um enunciado seguido de cinco alternativas: concordo inteiramente, concordo mais ou menos, nem concordo nem discordo, discordo mais ou menos 
e discordo inteiramente. Metade da escala é constituída por itens positivos, isto é, a concordância com o conteúdo do enunciado expressa atitudes sociais favoráveis à inclusão, e a outra metade por itens negativos, nos quais a concordância com o conteúdo dos enunciados indica atitudes desfavoráveis à inclusão. A escala de mentira serve como um indicador da confiabilidade das respostas, uma vez que a resposta aos seus itens é previsível, conforme se demonstrou durante o processo de validação do instrumento.

Para a análise dos dados da ELASI, preliminarmente foram calculados os escores da escala de mentira para todos os participantes e nenhum dos professores foi eliminado do estudo em função destes dados. Então, foi calculado um escore de atitudes sociais em relação à inclusão para cada respondente. Foram atribuídos valores, de acordo com a alternativa assinalada, segundo o seguinte critério: nos itens positivos, a nota 5 é para a alternativa concordo inteiramente, nota 4 para concordo mais ou menos, e assim por diante até a alternativa discordo inteiramente, que recebe a nota 1; nos itens negativos, o sentido de atribuição dos valores é invertido, isto é, a nota máxima é para a alternativa discordo inteiramente e a nota mínima, para concordo inteiramente. O escore total do indivíduo foi dado pela somatória das notas obtidas nos itens, sendo excluídos os itens da escala de mentira. O escopo da ELASI varia de 30 a 150.

Foi utilizada a Escala Infantil de Mensuração de Atitudes Sociais em relação à Inclusão para a coleta de dados com os alunos em todas as etapas. A escala é composta por 20 itens que apresentam afirmações sobre inclusão e três alternativas de respostas (sim, não e não sei). Foi elaborada a partir de estudos realizados pelo mesmo grupo de pesquisa e é usada para mensurar as atitudes sociais de crianças em relação à inclusão (BALEOTTI; OMOTE, 2003).

Com as respostas aos itens da Escala Infantil, foi calculado um escore de atitudes sociais em relação à inclusão para cada respondente. Primeiramente foram atribuídos pontos às respostas dadas a cada item, com os valores convencionados $-1,0$ ou 1 . $O$ valor -1 foi atribuído quando o respondente discordou do enunciado favorável à inclusão ou concordou com o enunciado desfavorável à inclusão; o valor 1, quando o respondente concordou com o enunciado favorável à inclusão ou discordou do enunciado desfavorável à inclusão; e o valor 0 foi atribuído quando o respondente assinalou que não sabia opinar a respeito do conteúdo do enunciado. Os escores individuais de cada respondente foram calculados somando-se algebricamente os pontos obtidos em cada um dos itens. O escore total de um participante podia variar de $-20 \mathrm{a}+20$.

Após a aprovação pelo CEP, o projeto foi apresentado aos professores e, concluídos os esclarecimentos, o TCLE foi assinado por aqueles que concordaram em participar das 
atividades. Os docentes foram capacitados para explicar aos alunos os objetivos da pesquisa, procedimentos e questões éticas de modo claro e em linguagem acessível, logo após consentirem em participar da pesquisa. Os estudantes foram informados sobre a pesquisa e os termos assinados pelos responsáveis. O pedido de consentimento aos responsáveis pelos alunos foi referente à participação na coleta de dados da pesquisa, não incluindo a participação nos encontros do programa informativo desenvolvido pelos professores em sala de aula. Aqueles que não tiveram os TCLE assinados por seus responsáveis participaram do programa informativo, mas não da coleta de dados. Os aspectos éticos envolvidos nessa etapa serão discutidos no item "Resultados e Discussão".

As etapas de coleta de dados e de intervenção, chamadas de capacitação dos professores e programa informativo, foram desenvolvidas em duas fases. A primeira fase foi composta por: a) pré-teste com todos os professores e alunos do GE e do GC, b) intervenção, composta por capacitação dos professores do GE e aplicação do programa informativo aos alunos do GE, e c) pós-teste com os professores e alunos do GE e segundo pré-teste com professores e alunos do GC. Na segunda fase, realizaram-se: a) intervenção, composta por capacitação dos professores do GC e aplicação do programa informativo aos alunos do GC e b) pós-teste com alunos e professores do GC e o follow up com professores do $\mathrm{GE}^{3}$. A Figura 1 ilustra as etapas desenvolvidas ao longo da pesquisa.

Figura 1 - Fases da pesquisa e suas etapas em cada grupo ao longo do tempo ${ }^{4}$

\footnotetext{
${ }^{3}$ Não foi realizado o follow up com os alunos do GE em função do período letivo, pois o follow up com os professores ocorreu na última semana de aula, quando os alunos já estavam iniciando as férias.

${ }^{4} \mathrm{O}$ eixo dos $\mathrm{x}$ na Figura 1 representa a sequência das semanas em que ocorreram os eventos e não as semanas do calendário anual. A aplicação da ELASI e da Escala Infantil nas diferentes etapas ocorreu com um intervalo de tempo de uma semana entre o GE e o GC, em função da possibilidade de operacionalização, pois a disponibilidade dos professores era apenas no HEC, que ocorria em ambas as escolas no mesmo dia da semana e horário. Assim, em uma determinada semana realizou-se a aplicação da ELASI e da Escala Infantil no GE, e na semana seguinte, no GC.
} 


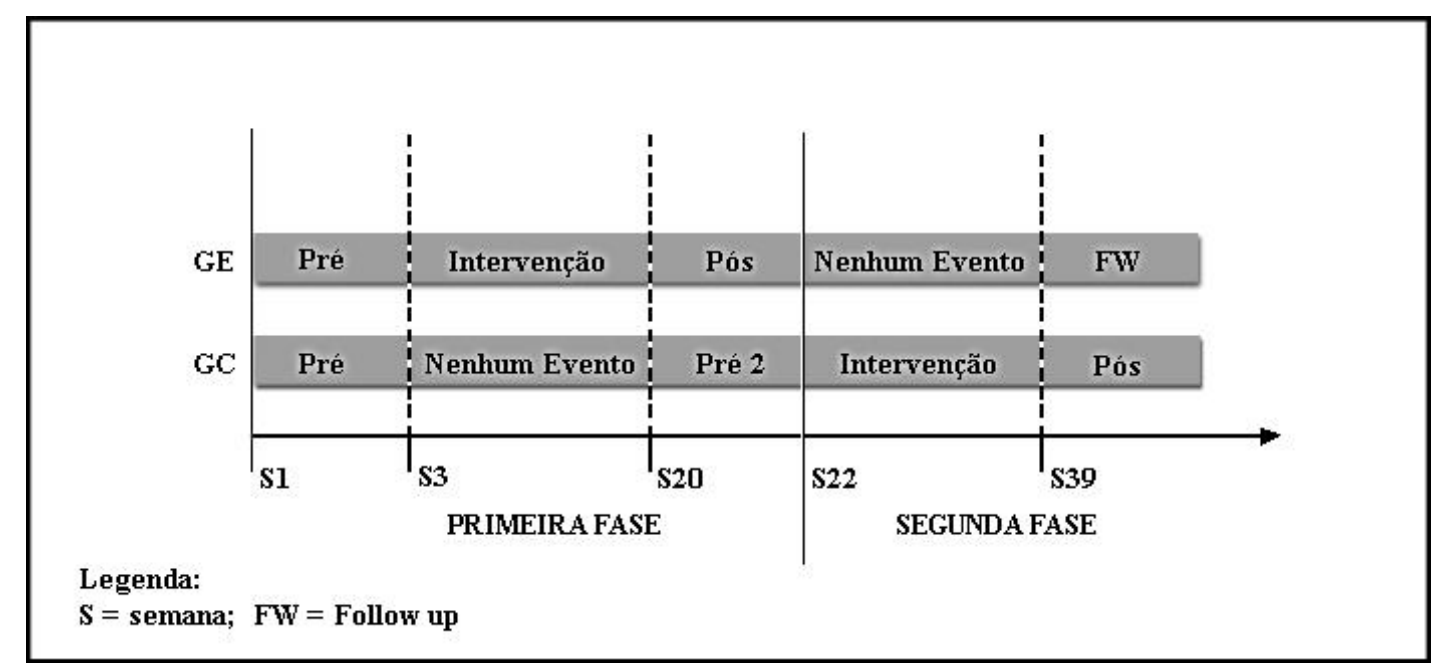

Fonte: Autoria própria

\section{Primeira fase}

Foi realizada a avaliação inicial das atitudes sociais de todos os professores tanto do GC quanto do GE, sendo que para metade foi aplicada a forma A e para outra metade a forma B. A entrega de cada versão aos participantes foi feita aleatoriamente. As formas A e B da ELASI foram construídas para serem equivalentes, porém podem ocorrer diferenças dependendo das características das amostras, razão pela qual foi utilizada a técnica de balanceamento (CAMPBELL; STANLEY, 1979), que consistiu no procedimento em que cada metade respondeu a uma das formas e, como será descrito adiante, a inversão das formas quando da segunda avaliação.

A aplicação foi feita de forma monitorada, ou seja, informações adicionais foram fornecidas e eventuais dúvidas acerca do preenchimento da escala foram esclarecidas, com o cuidado para não passar informações que pudessem afetar as respostas dos participantes. A aplicação foi coletiva, durante o Horário de Estudo Coletivo (HEC) de cada escola, que ocorria semanalmente no turno contrário ao do trabalho. Após o pré-teste, os professores aplicaram a Escala Infantil em seus alunos mediante capacitação prévia tanto do GE quanto do GC.

$\mathrm{Na}$ sequencia, foi desenvolvida a capacitação apenas para os professores do GE. O objetivo dessa intervenção foi o de capacitá-los para aplicarem a seus alunos um programa informativo sobre a temática das deficiências e da inclusão voltado ao público infantil, adaptado de estudos anteriores (FERREIRA, 1998; VIEIRA; DENARI, 2012). Foram realizados sete encontros com os professores, com duração de uma hora e meia cada, com periodicidade quinzenal. A capacitação ocorreu no HEC. Logo após cada encontro, os slides 
da exposição dialogada eram encaminhados para todos os professores por email e os materiais a serem utilizados juntos aos alunos eram fornecidos. Nas semanas em que não ocorreram os encontros presenciais, os professores realizaram com seus estudantes os encontros do programa para os quais foram capacitados.

Concluídas todas as etapas da capacitação, foi realizada uma segunda avaliação das atitudes sociais dos professores tanto do GE quanto do GC. A segunda avaliação se caracterizou como pós-teste para o GE e pré-teste2 para o GC. Obedecendo à técnica de balanceamento, desta vez a metade dos professores que havia respondido a forma A da ELASI respondeu a forma B e vice-versa. A inversão das versões apresentadas foi realizada por dois motivos: (1) na hipótese de as formas A e B não serem rigorosamente equivalentes nas amostras utilizadas nesta pesquisa, possíveis diferenças de uma forma em relação a outra estariam presentes igualmente nas duas avaliações; e (2) para evitar ou minimizar o chamado efeito teste-reteste, que consiste em eventual viés decorrente da aplicação do mesmo instrumento em curto período de tempo (CAMPBELL; STANLEY, 1979). Quanto aos alunos, foi aplicada a Escala Infantil a todos os estudantes tanto do GE quanto do GC, por seus respectivos professores, sendo considerado pós-teste para o GE e pré-teste2 para o GC

\section{Segunda fase}

Foi realizada a mesma capacitação da primeira fase, agora apenas com os professores do GC. Nesse período, os professores do GE não tiveram nenhuma atividade relacionada ao projeto. Após a capacitação do GC, foi realizada uma nova avaliação das atitudes sociais dos professores, servindo como pós-teste para o GC e como follow up para o GE, 18 semanas após o término de sua capacitação, para avaliar a manutenção das mudanças observadas anteriormente. A versão aplicada para cada metade foi a mesma da primeira avaliação. Foi aplicada a Escala Infantil apenas aos estudantes do GC, por seus professores, funcionando como um pós-teste para este grupo (ver nota de rodapé 3).

Posteriormente, foram realizadas análises estatísticas para a verificação das diferenças entre os grupos de professores e entre os grupos de alunos em todas as etapas da pesquisa, utilizando a Prova de Mann-Whitney. Foram também realizadas análises intragrupos por meio da prova de Wilcoxon.

\section{RESULTADOS E DISCUSSÃO}


Os resultados obtidos indicaram que o programa informativo aplicado pelos professores em seus alunos produziu efeitos positivos nas atitudes sociais tanto do alunado quanto dos próprios professores, tornando-as mais favoráveis à inclusão (VIEIRA, 2017).

Para o desenvolvimento da presente pesquisa, elaborou-se um delineamento cuidadoso para investigar os efeitos desta intervenção nas atitudes sociais tanto dos estudantes quanto dos professores, considerando o rigor científico necessário para estudos desta natureza, destacados por Omote (2003) e Scior (2011), e nem sempre adotados.

Vários pontos da pesquisa podem ser discutidos em relação aos aspectos metodológicos e éticos, destacando-se alguns deles a seguir.

\section{1. Tipo de pesquisa e delineamento adotados}

As pesquisas quase-experimentais não contemplam o controle das variáveis estranhas com a mesma eficiência das pesquisas experimentais. Conclusões sobre a eventual relação causal encontrada entre a intervenção e o resultado obtido se enfraquecem na medida em que hipóteses concorrentes podem explicar os resultados obtidos (DUTRA; REIS, 2016). Além da intervenção, podem ocorrer outros fatos com os professores e alunos que modificam suas atitudes, como campanhas de conscientização sobre as deficiências na escola, programas televisivos, vídeos na internet, nascimento de familiares com deficiências. Para ampliar a segurança do estudo, nesta pesquisa foi constituído um grupo controle.

Outra dificuldade encontrada na prática é a distribuição aleatória dos participantes em grupos, sempre que se utilizam grupos naturalmente constituídos, como é comum nas pesquisas em Educação e Educação Especial. Tal fato não permite garantir sua equivalência no começo do estudo, o que pode comprometer a validade interna e enfraquecer as conclusões sobre a relação causa-efeito que se pretende demonstrar (DUTRA; REIS, 2016).

$\mathrm{O}$ delineamento empregado na presente pesquisa procurou diminuir essas limitações. Como não havia garantia da equivalência entre o GE e o GC, tanto de professores quanto de estudantes, foi feita uma avaliação preliminar das atitudes sociais em relação à inclusão. A comparação dos escores obtidos por GE e GC revelou haver equivalência estatística antes de iniciar qualquer intervenção.

Este tipo de desenho pode ser chamado de delineamento de pré e pós-teste com grupo controle não equivalente (SELLTIZ; WRIGHTSMAN; COOK, 1976). Inclui informações de pré-teste dos grupos para verificar a equivalência entre eles. Evidenciada a equivalência estatística entre os grupos em relação à variável sob estudo, no início do experimento, 
delineamento de grupos experimental e controle não constituídos aleatoriamente apresenta melhor validade interna.

\section{2. Momentos de mensuração da variável dependente: pré-teste, pós-teste e follow up}

O pré-teste em ambos os grupos, tanto de professores quanto de estudantes, foi uma condição necessária para assegurar a equivalência entre o GE e o GC, que não puderam ser constituídos randomicamente. Somente após a verificação da equivalência estatística entre esses grupos, foi possível realizar intervenções com o intuito de se estudarem os efeitos delas. Essa comparação forneceu indício de que os grupos de professores não eram diferentes ( $\mathrm{p}=$ 0,53), assim como os grupos de alunos ( $\mathrm{p}=0,52)$.

A realização do pré-teste poderia gerar dois tipos de vieses: o de testagem, especialmente no que se refere ao efeito teste-reteste (CAMPBELL; STANLEY, 1979), com a utilização do mesmo instrumento em repetidas mensurações, e a possibilidade de a avaliação preliminar interagir com a intervenção, no sentido de que os participantes podem ter sido sensibilizados com aquela avaliação.

$\mathrm{O}$ viés do teste-reteste pode ter sido minimizado pelo intervalo relativamente longo entre as avaliações (18 semanas) e principalmente pelo uso de duas formas equivalentes de mensuração, devidamente balanceadas, no caso dos professores. A Escala Infantil não possui formas equivalentes, porém o intervalo de 18 semanas entre uma avaliação e outra pode ter minimizado eventual efeito teste-reteste.

Eventual interação entre a avaliação inicial e a intervenção subsequente não pode ser controlada no delineamento empregado. Seriam necessários GE e GC constituídos para serem equivalentes por meio de procedimentos estatísticos adequados, de tal sorte que fosse dispensável a avaliação anterior à intervenção. Em pesquisas como esta, a constituição de grupos equivalentes, por meio de procedimentos adequados de sorteio, vai de encontro a preceitos éticos e a condições organizacionais da instituição na qual se realiza a pesquisa.

A segunda avaliação, referida por pós-teste no GE e por pre-teste 2 no GC, serviu para verificar com segurança os efeitos da intervenção. A comparação dos escores do pós-teste com os do pre-teste, no GE, indicou haver diferença estatisticamente significante, tornando-se as atitudes sociais em relação à inclusão mais favoráveis após a intervenção tanto nos professores $(\mathrm{p}<0,001)$ quanto nos alunos $(\mathrm{p}<0,0001)$, fornecendo uma evidência dos efeitos da intervenção sobre as atitudes sociais em relação à inclusão. A comparação dos escores do pós-teste, do GE, com os escores do pre-teste2, do GC, também indicou haver diferença 
estatisticamente significante, tanto entre os professores $(\mathrm{p}<0,01)$ quanto entre alunos $(\mathrm{p}<$ 0,0001), fortalecendo a conclusão sobre os efeitos positivos da intervenção. Se, por hipótese, a mudança verificada nas atitudes sociais no GE fosse devida a algum outro evento havido nesse período, o mesmo efeito teria sido observado no GC.

A terceira avaliação, referida por follow up, no GE dos professores, e por pós-teste, no GC de professores e de alunos, teve dois propósitos: verificar a manutenção da mudança havida, no GE dos professores, após 18 semanas, e avaliar os efeitos da intervenção no GC realizada na segunda fase do experimento.

A qualquer intervenção que pretende produzir mudanças em atitudes sociais ou ações interessa garantir a manutenção das mudanças ocorridas, razão pela qual se realizam avaliações algum tempo após o encerramento da intervenção. A comparação dos escores do follow up com os do pós-teste, no GE dos professores, indicou não haver diferença significante $(\mathrm{p}=0,56)$ sugerindo a manutenção das mudanças ocorridas. Adicionalmente, foi feita a comparação dos escores do follow up com os do pós-teste do GC, verificando-se também não haver diferença estatisticamente significante $(\mathrm{p}=0,55)$.

Para assegurar maior confiabilidade das conclusões sobre os efeitos da intervenção praticada sobre as atitudes sociais em relação à inclusão, tanto entre os professores quanto entre os alunos, foi necessária a realização de mensuração da variável dependente nessas três ocasiões.

\subsection{Replicação intra-delineamento ou série histórica}

Em delineamentos de grupos, com ou sem pré-teste, habitualmente apenas o grupo experimental é submetido à intervenção. No presente experimento, o grupo controle também foi submetido à intervenção em um outro momento, após concluída a fase de intervenção no grupo experimental.

Esse tipo de delineamento pode fornecer algum indício sobre a possibilidade de o resultado se dever a algum outro evento ocorrido no mesmo tempo em que era realizada a intervenção. Se o outro grupo submetido ao mesmo procedimento, em momento distinto, produzir resultado que confirma o do primeiro grupo, com mais segurança pode-se sugerir que a mudança havida se deveu à intervenção e não a um evento fortuito estranho ao experimento.

Constitui-se numa espécie de replicação intra-delineamento. Replicar significa pesquisar de novo, com o objetivo de investigar e comparar resultados, definir e/ou validar 
teorias. Há vários tipos de replicação, algumas se caracterizam pela reprodução total dos procedimentos metodológicos de um estudo e outras são parciais, pois introduzem mudanças deliberadas em alguns aspectos do estudo original, visando a generalização e ampliação do escopo da pesquisa (MORRISON; MATUSZEK; SELF, 2010). O objetivo deste tipo de replicação é verificar se variáveis não controladas ou desconhecidas podem ser capazes de interferir no resultado. A replicação do procedimento realizado, inicialmente com GE e em um segundo momento com o GC, fortaleceu a confiabilidade das conclusões, já que resultados semelhantes foram obtidos quando as mesmas condições experimentais foram repetidas com outra amostra e em outro momento.

\subsection{Os professores como participantes e colaboradores}

O objetivo maior desse estudo referia-se a mudança de atitudes sociais dos professores em relação à inclusão. Procedimento utilizado pelos professores com seus alunos já havia sido empregado anteriormente com resultados positivos, aplicando-o diretamente aos estudantes (VIEIRA e DENARI, 2012). Ao capacitar os professores para que eles administrassem o programa informativo aos seus alunos, havia, naturalmente, o interesse em verificar a possibilidade de produzir mudança nas atitudes sociais de alunos por intermédio de ações praticadas por seus professores. Mas, acima de tudo, havia interesse em estudar os efeitos do envolvimento dos professores em procedimento dessa natureza sobre as suas próprias atitudes sociais, como as técnicas de mudança de atitudes sociais fazem crer (RODRIGUES; ASSMAR; JABLONSKI, 2005).

A execução do programa formativo dependeu do envolvimento dos professores em todo o processo, sua participação nos encontros presenciais, o preparo dos materiais solicitados e a aplicação em suas salas de aula dos conteúdos e estratégias para os quais foram capacitados. Com todo esse investimento para administrar um programa que tinha o propósito explícito de modificar as atitudes sociais de alunos em relação à inclusão, os professores acabaram por modificar as suas próprias atitudes sociais.

O delineamento empregado apresenta pelo menos três aspectos vantajosos: (1) com a coparticipação dos professores na tarefa de se criarem atitudes sociais favoráveis à inclusão entre os alunos, condição essa importante para a inclusão bem sucedida de alunos públicoalvo da Educação Especial, amplia-se expressivamente o alcance de projetos com tal finalidade; (2) a familiaridade e a relação de confiança estabelecida entre os professores e seus alunos podem contribuir para o bom andamento do programa informativo; (3) a relação 
de cumplicidade que se pode estabelecer entre os professores e seus alunos durante o desenvolvimento do programa informativo pode contribuir para a manutenção das mudanças ocorridas em ambas as partes.

A experiência de cada professor com seus alunos facilitou a explicação da pesquisa por meio de uma linguagem e estratégias compreensíveis e a relação de confiança estabelecida entre as partes pode ter colaborado para a livre expressão das crianças sobre seu desejo de participar ou não. Conforme Sigaud et al. (2009), a presença de um adulto de confiança gera segurança tanto para a criança participar com tranquilidade das pesquisas quanto para ter maior liberdade de se negar ou desistir.

\subsection{Alternativas para atender a demandas éticas.}

Apesar de o uso de GC ampliar a confiabilidade de estudos quase-experimentais, há certo dilema ético em delineamentos com grupos controle. De acordo com Dutra e Reis (2016), quando há evidências suficientes de benefícios em determinadas intervenções, a participação de um grupo controle não seria ética. Os CEPs têm exigido cuidados em relação à sua utilização, no sentido de os sujeitos não serem meramente objetos das pesquisas, sem que tenham retorno ou benefício direto ou ainda, sob outra perspectiva, sofram até certo prejuízo por lhes ser negado acesso a intervenções que poderiam auxiliá-los de alguma forma.

Ao replicar a intervenção realizada inicialmente com o GE em um momento distinto com o GC, foi possível disponibilizar a todos os participantes do estudo o acesso aos possíveis benefícios da capacitação e do programa informativo. Se não houvesse esta segunda fase, não seriam ensejados ao GC a capacitação, o acesso a informações e materiais sobre o tema, o espaço de debate a respeito da inclusão em seu cotidiano escolar e o subsídio à aplicação do programa informativo junto a seus alunos, tendo sido negados esses possíveis benefícios aos membros do GC. Esses benefícios dizem respeito a atitudes sociais mais favoráveis de professores e alunos, o que sabidamente interfere no ambiente escolar, tornando-o mais acolhedor em relação à diversidade. A presença na classe de um aluno com expressiva diferença nas necessidades educacionais, acolhido e integrado produtivamente, representa certamente benefício para todos os envolvidos. Por tudo isso, concluída a primeira fase da pesquisa, todo o procedimento foi replicado junto ao $\mathrm{GC}$, atendendo a esta demanda ética de propiciar a todos os sujeitos participantes o acesso a possíveis benefícios da intervenção. 
Adicionalmente, ao final da pesquisa, foi feita a devolutiva aos participantes dos resultados obtidos, para que também participassem do regozijo de terem coletivamente alcançado a meta estabelecida no projeto em benefício de todas as partes envolvidas. Esta é uma etapa final do trabalho de inegável importância ética, que deve ser cumprida sempre.

Considerando as demandas éticas relacionadas à pesquisa com crianças, a exigência da assinatura do TCLE merece destaque. Compreende-se a necessidade de os indivíduos serem informados sobre o estudo e decidirem voluntaria e formalmente sobre sua participação na pesquisa, no sentido de preservação de sua autonomia e integridade, porém há que se considerar alguns aspectos pouco discutidos nos comitês e nos debates entre os pesquisadores.

Os autores confrontaram-se com o dilema de solicitar aos pais ou responsáveis pelos alunos a permissão para que estes participassem de um programa informativo a ser desenvolvido em sala de aula pelos próprios professores. Aventou-se a possibilidade de alguns pais recusarem a participação de seus filhos ou não assinarem os TCLE por outros motivos e foram discutidas possíveis implicações disso na prática. Ponderou-se que as crianças impedidas de participar ficariam excluídas de atividades que poderiam ser benéficas a elas, consistindo em atividades educativas junto com seus colegas e com seus próprios professores. Constituem benefícios o aprendizado de novos conceitos e a revisão de suas crenças e sentimentos, o que pode favorecer o convívio satisfatório com algum colega com necessidades educacionais especiais.

As crianças impedidas de participar da pesquisa, por não ter sido assinado o TCLE pelos pais ou responsáveis, poderiam sentir-se excluídas do grupo ao qual pertence, eventualmente criando situações delicadas, caracterizadas como novos problemas éticos, produzidos pelo próprio procedimento que, em princípio, tem a função de protegê-las. Se o TCLE tem o propósito de assegurar a integridade e o bem estar dos participantes de pesquisa, deve ser assinado para a participação em pesquisas cujos procedimentos podem representar risco potencial aos participantes. Muitas pesquisas, sobretudo nas áreas de Educação e Educação Especial, trazem benefícios aos participantes.

Assim, os autores consideraram que a exclusão de qualquer criança da intervenção poderia acarretar riscos ou danos a ela. De acordo com Fernandes (2016), é necessário ponderar os interesses de quem realiza as pesquisas e as prioridades, dos pais, das crianças, do pesquisador ou da sociedade. Os critérios de inclusão ou exclusão precisam ser muito cuidadosos nesses casos, pois a intenção de proteger ou poupar as crianças pode privá-las de expressarem-se, participarem de atividades interessantes para a formação de suas identidades 
cidadãs e sua autonomia, pois sentirem-se sujeitos das decisões que dizem respeito a elas próprias é essencial (FRANCISCHINI; FERNANDES, 2016).

$\mathrm{O}$ envolvimento em pesquisas que consideram as necessidades das crianças pode ser vivenciado de modo positivo, sendo uma oportunidade de serem ouvidas atentamente pelos adultos, em uma relação de confiança, e expressarem suas próprias ideias. Ao participarem de um estudo, a atenção recebida e o sentimento de pertencimento a um grupo podem ser gratificantes para as crianças (SIGAUD et al., 2009).

Considerando todas essas ponderações, optou-se por submeter ao CEP (e o parecer obtido foi favorável) um TCLE que solicitasse aos responsáveis apenas a permissão da participação de seus filhos na coleta de dados da pesquisa, ou seja, na aplicação da Escala Infantil e na utilização de seus dados para o estudo, mas não na participação deles nos encontros do programa informativo desenvolvido pelos professores em sala de aula. Tanto a Direção e a Coordenação da escola quanto o professor responsável pela classe tinham condições de decidir se o conteúdo e as atividades do programa informativo eram pertinentes e se deveria ser ministrado a seus alunos, como uma atividade extracurricular. $\mathrm{Na}$ avaliação deles, o programa não incluía riscos às crianças e a exclusão de qualquer estudante destas atividades poderia implicar questões éticas, por negar-lhe a participação em uma atividade considerada importante pelos educadores, além da possibilidade de sentir-se excluído no ambiente escolar.

Assim, o programa informativo foi aplicado em sala de aula para todos os estudantes. Aqueles que não tiveram os TCLE assinados por seus responsáveis participaram dos encontros para a execução das atividades do programa, mas não da coleta de dados.

Os aspectos éticos na pesquisa vão além das tarefas burocráticas, rigidamente normatizadas, e exigem reflexão e flexibilidade do pesquisador, considerando que os protocolos não são estáticos, precisam ser dinâmicos, renegociados, considerando os sujeitos envolvidos e os diversos contextos possíveis (FERNANDES, 2016). A ética na pesquisa precisa pautar-se por princípios e não por um conjunto de normas a serem cumpridas cegamente.

\section{CONCLUSÕES}

Os resultados obtidos indicaram que a intervenção modificou as atitudes sociais dos professores e alunos que passaram por ela em relação à inclusão. A replicação do procedimento realizado em um primeiro momento com o GE, posteriormente com GC, 
fortaleceu a confiabilidade do experimento, pois se reafirmaram os efeitos do programa informativo, que em outro grupo, em um diferente momento, também produziu mudanças significativas nas atitudes sociais dos professores, tornando-as mais favoráveis. Ademais, com o follow up, verificou-se que as mudanças ora observadas junto ao GE de professores logo após sua intervenção, mantiveram-se depois de transcorridas 18 semanas.

Destaca-se que neste formato de intervenção, no qual o pesquisador capacitou outros sujeitos para desenvolverem as atividades, percebe-se o potencial de ampliação do alcance dos efeitos pretendidos. Os docentes tornaram-se importantes multiplicadores do processo de formação para inclusão, pois poderão utilizar-se das experiências vivenciadas com outros alunos, em anos posteriores, algo que intervenções mais pontuais, aplicadas por profissionais externos ao ambiente escolar ou apenas pela própria pesquisadora, não poderiam abranger. Além disso, a inovação da intervenção está no fato de os professores mudarem suas próprias atitudes ao tentarem modificar as de seus alunos.

O presente estudo apresentou um delineamento rigoroso do ponto de vista científico de modo a utilizar-se de procedimentos diversos que visaram controlar possíveis vieses da pesquisa. Ademais, buscou alternativas inovadoras para atender a demandas éticas importantes, garantindo o acesso aos benefícios da intervenção a todos os participantes. Também evitou a exclusão e constrangimentos dos alunos no ambiente escolar em função de sua participação ou não no estudo.

Destaca-se a importância de um planejamento também do ponto de vista ético no processo de elaboração de um projeto de pesquisa, pois há situações que podem ser previstas e evitadas, desde que sejam consideradas como possibilidades e que os pesquisadores estejam dispostos a criar alternativas nem sempre convencionais e descritas nos protocolos para sua superação. Outras tantas ocorrências podem surgir no percurso e também cabe aos pesquisadores lhes darem a devida atenção e buscarem novas formas de enfrentamento, prezando pelo bem estar dos participantes e pela construção de um conhecimento consistente.

Conclui-se, enfim, que é possível, na concepção de uma pesquisa, levar rigorosamente em conta pelo menos parte dos preceitos de um delineamento cuidadoso que permita emprestar aos resultados uma maior confiabilidade e reduzir a possibilidade de se gerarem artefatos experimentais, isto é, dados produzidos e enviesados pelo próprio delineamento empregado. Semelhantemente, é possível, pelo menos em parte, minimizar a possibilidade de se criar uma situação eticamente discutível, em decorrência da eventual negativa da parte dos responsáveis pela participação de crianças na pesquisa. 


\section{REFERÊNCIAS}

BALEOTTI, L. R.; OMOTE, S. Atitudes sociais de alunos do ciclo I do Ensino Fundamental em relação à inclusão: construção de uma escala infantil. In: SIMPÓSIO EM FILOSOFIA E CIÊNCIA, 5 - Trabalho e conhecimento: desafios e responsabilidades das ciências, 2003, Marília. Anais eletrônico. Marília: UNESP Marília Publicações, 2003. 1 CD-ROM.

CAMPBELL, D. T.; STANLEY, J. C. Delineamentos experimentais e quase-experimentais de pesquisa. São Paulo: EPU, 1979.

DUTRA, H. S.; REIS, V. N. dos. Desenhos de estudos experimentais e quase-experimentais: definições e desafios na pesquisa em enfermagem. Rev enferm UFPE on line. Recife, v. 10, n. 6, p. 2230-41, 2016. DOI: 10.5205/reuol.9199-80250-1-SM1006201639

FERNANDES, N. Ética na pesquisa com crianças: ausências e desafios. Revista Brasileira de Educação, v. 21, n. 66, 2016. http://dx.doi.org/10.1590/S1413-24782016216639

FERREIRA, S. L. Aprendendo sobre a deficiência mental: um programa para crianças. São Paulo: Memnon, 1998.

FRANCISCHINI, R.; FERNANDES, N. Os desafios da pesquisa ética com crianças. Estudos de Psicologia. Campinas, v. 33, n. 1, p. 61-69, 2016. http://dx.doi.org/10.1590/198202752016000100007.

GAIVA, M. A. M. Pesquisa envolvendo crianças: aspectos éticos. Revista Bioética, v. 17, n. 1, p. 135- 46, 2009.

GARCÍA, M. A. F.; DÍAZ, A. L. A.; RODRÍGUEZ, M. A. A. Revisión y análisis de los programas de cambio de actitudes hacia personas com discapacidad. Anuario de Psicología Clínica y de la Salud / Annuary of Clinical and Health Psychology, v. 5, p. GAIVA, 2009-98, 2009.

GATTI, B. A. formação de professores, pesquisa e problemas metodológicos. Contrapontos, v. 3, n. 3, p. 381-392, 2003.

MORRISON, R; MATUSZEK, T.; SELF, D. Preparing a Replication or Update Study in the Business Disciplines. European Journal of Scientific Research, v. 47, n.2, p. 278-287, 2010.

OLIVEIRA, A. A. O Processo de inclusão no Brasil: políticas públicas para o educando com necessidades educacionais especiais. In: GENARO, K. F.; LAMÔNICA, D. A. C.; BEVILACQUA, M. C. O Processo de comunicação: contribuição para a formação de professores na inclusão de indivíduos com necessidades educacionais especiais. São José dos Campos, SP: Pulso Editora, 2006.

OMOTE, S. A Construção de uma escala de atitudes sociais em relação à inclusão: notas preliminares. Revista Brasileira de Educação Especial, Marília, v. 11, n. 1, p. 33-47, 2005 
A Pesquisa em educação especial. In: MARQUEZINE, M. C.; ALMEIDA, M. A.; OMOTE, S. Colóquios sobre pesquisa em Educação Especial. Londrina: Eduel, 2003. p. xvii-xxi.

OMOTE, S. et al. Mudança de atitudes sociais em relação à inclusão. Paidéia, v. 15, n. 32, p. 387-398, 2005.

SANTOS, M. T. P. dos. Olhares sobre a diferença: representações de crianças e jovens. 2006. Dissertação (Doutorado em Psicologia Aplicada - Psicologia da Educação) Universidade Nova de Lisboa, Instituto Superior de Psicologia Aplicada, 2006.

SCIOR, K. Public awareness, attitudes and beliefs regarding intellectual disability: a systematic review. Research in Developmental Disabilities, v. 32, p. 164-2182, 2011. DOI: 10.1016/j.ridd.2011.07.005.

SELLTIZ; WRIGHTSMAN; COOK. Métodos de pesquisa nas relações sociais: delineamentos de pesquisa. São Paulo: E.P.U., 1976. v. 1

SIGAUD, C. H. de S. et al. Aspectos éticos e estratégias para a participação voluntária da criança em pesquisa. Rev Esc Enferm USP, v. 43 (Esp 2), p. 1342-6, 2009.

VIEIRA, C. M. Atitudes sociais em relação à inclusão: efeitos da capacitação de professores para ministrar programa informativo aos alunos. 2014. $183 \mathrm{f}$. Tese (Doutorado em Educação) - Universidade Estadual Paulista, Faculdade de Filosofia e Ciências, Marília, 2014.

Mudança de atitudes sociais de professores em relação à inclusão:

transformação junto com alunos. Revista Educação Especial, v. 30, n. 59, p. 723-736, 2017. Disponível em: https://periodicos.ufsm.br/educacaoespecial. DOI:

http://dx.doi.org/10.5902/1984686X28429. Acesso em: 10 nov. 2017.

VIEIRA, C. M; DENARI, F. E. Programa informativo sobre deficiência mental e inclusão: mudanças nas atitudes sociais de crianças sem deficiência. Rev. Bras. Ed. Esp. Marília, v.18, n.2, p. 265-282, 2012. 